\title{
Controlled trial of disodium cromoglycate in chronic persistent ulcerative colitis
}

\author{
N. A. BUCKELL, S. R. GOULD ${ }^{1}$, D. W. DAY ${ }^{2}$, J. E. LENNARD-JONES ${ }^{3}$, AND \\ A. M. EDWARDS
}

From St Mark's Hospital, City Road, London, and Pharmaceutical Division, Fisons Limited, Loughborough

SUMMARY Oral disodium cromoglycate ( $200 \mathrm{mg}$ qds) has been tested in 26 patients with ulcerative colitis that was resistant to medical treatment. In a double-blind crossover trial disodium cromoglycate and placebo were added to conventional treatment in random order, each for four weeks. There was no significant difference in therapeutic effect between disodium cromoglycate and placebo.

Some patients with ulcerative colitis are resistant to treatment with sulphasalazine and corticosteroids and appear to need additional therapy. Beneficial effects of disodium cromoglycate have been reported in the treatment of chronic proctitis (Heatley et al., 1975) and the long-term management of patients with slightly active total ulcerative colitis (Mani et al., 1976). There has also been a preliminary report of disodium cromoglycate in the maintenance of remission of ulcerative colitis (Dronfield and Langman, 1977).

In this trial the effect of adding disodium cromoglycate to an apparently ineffective conventional regime has been studied in patients with active ulcerative colitis.

\section{Methods}

\section{PATIENTS STUDIED}

Patients with ulcerative colitis diagnosed on the basis of the history, sigmoidoscopic findings, rectal biopsy appearances, and double contrast barium enema examination and in whom the disease had shown persistent activity for at least two months were studied. Activity has been defined as a bowel frequency of three or more per 24 hours with or without macroscopic blood in the stools and an abnormal appearance on sigmoidoscopy.

Present address: 'Department of Medicine, The London Hospital, London.

Present address: ${ }^{2}$ Department of Pathology, New Medical School, University of Liverpool, Liverpool.

${ }^{3}$ Address for reprint requests: Professor J. E. Lennard-Jones, St Mark's Hospital, City Road, London EC1V 2PS.

Received for publication 20 September 1978

\section{Exclusions and withdrawals}

Patients were entered into the study only after a full explanation had been given and their consent obtained. One patient was withdrawn because of severe symptoms which developed during the first (placebo) period of treatment and another patient was excluded from the analysis because of failure to take the active treatment.

Twenty-six patients completed the trial and form the basis of this report.

DESIGN OF TRIAL

Each patient was randomly allocated to treatment with oral disodium cromoglycate $200 \mathrm{mg}$ four times daily or identical placebo capsules containing glucose. The patient was instructed to swallow two capsules whole after each meal and before retiring at night. This treatment was continued for four weeks and the alternative treatment was then administered for the following four weeks. Neither the patient nor the assessing clinician knew which therapy was being given. Other treatment was continued unchanged.

\section{METHODS OF ASSESSMENT}

Patients were assessed on entry to the trial, after four weeks and after eight weeks at the end of the trial.

\section{Clinical assessment}

Where possible the three assessments were made by the same clinician. At each assessment bowel frequency by day and night, rectal bleeding (none, trace, with every stool or blood alone), urgency (the number of minutes for which the patient could resist the call to stool), incontinence, general well-being, body weight, and ability to work and 
perform usual activities during the previous seven days were recorded. The sigmoidoscopic appearances were graded (Baron et al., 1964). The patient's and assessing clinician's opinion of whether the colitis was better, the same, or worse than during the previous month was noted.

Besides routine haematological and biochemical measurements, the serum seromucoid, which correlates with the activity of ulcerative colitis (Cooke et al., 1958), was measured.

\section{Rectal biopsies}

A rectal biopsy was taken at each assessment. The three biopsies from each patient were ranked in order of severity of inflammation according to standard histological criteria (Morson, 1974) by a histopathologist who was unaware as to the order in which the two treatments had been given. The second biopsy was compared with the first, and the third with the second (Table 3).

Eight of the 26 biopsies taken at the first assessment were well orientated when examined histologically. These biopsies were stained with azoeosin (which differentially stains eosinophils) and all the eosinophils in the lamina propria of the mucosa counted using an eyepiece graticule. The eosinophil density throughout the lamina propria of each biopsy was calculated by dividing the total number of eosinophils by the area of the lamina propria (Day, in preparation).

\section{Diary cards}

Diary cards were kept by all the patients throughout both treatment periods. The bowel frequency by day and night, the amount of rectal bleeding, the degree of urgency, and the number of episodes of incontinence were recorded. Data recorded during the last seven days of each treatment period were analysed.

\section{PATIENT COMPLIANCE}

Capsules which had not been taken were returned and counted by the assessing clinician after each treatment. The patient also recorded the number of capsules taken each day on the diary card.

\section{ANALYSIS OF RESULTS}

Two-tailed non-parametric statistics were used to assess significance of observed changes except in the case of body weight and laboratory variables which were analysed using Student's $t$ test.

\section{Results}

TREATMENT GROUPS

Details of the patients studied are shown in Table 1.
Table 1 Details of patients on entry to study

\begin{tabular}{lll}
\hline & Number of patients \\
\hline Patients and sex & 16M & 10F \\
Age (yr) & Mean 47.6 & Range 12-72 \\
Duration of colitis (yr) & Mean 9.5 & Range 1.4-24 \\
Previous hospital admission(s) & & 14 \\
Duration of present symptoms & & 5 \\
>1 year & 12 \\
>6 months & 9 \\
<6 months & 2 \\
Extent of disease: & 2 \\
Normal barium enema & 10 \\
Rectum and sigmoid colon & 8 \\
Splenic flexure and distal colon & & 6 \\
Proximal to splenic flexure & & \\
\hline
\end{tabular}

All the patients were receiving regular treatment with steroid retention enemas, six were taking prednisolone by mouth, and 19 of the 26 were taking sulphasalazine. Fourteen patients had required hospital admission for treatment of colitis in the past.

\section{PATIENT COMPLIANCE}

Analysis of the diary cards showed that an average of 7.5 active treatment and $7 \cdot 3$ placebo treatment capsules were taken each day and this agreed closely with the number calculated from the returned capsules.

\section{COMPARISON OF DISODIUM CROMOGLYCATE}

AND PLACEBO TREATMENTS

There was no significant difference in any of the variables studied between disodium cromoglycate and placebo treatments (Table 2). There was also no evidence of a delayed response during the second (placebo) month among those patients who had received the active treatment first. Analysis of the diary cards showed close agreement with the clinical assessments. Rectal urgency was not analysed because of the wide individual variation recorded and incontinence occurred in too few patients (three in each group) for statistical analysis; there was no apparent difference, however, in these parameters between the two treatments. The similarity of presentation of the two treatment order groups can be seen. There was a significant tendency for each variable to improve throughout the trial, particularly in the first month. During the first month there were significant reductions in the bowel frequency and serum seromucoid concentrations in both the treatment groups; similarly, in those patients receiving placebo during the first month, both the rectal bleeding and sigmoidoscopic appearances significantly improved. There was a significant improvement in the rectal biopsy ranking $(P<0.01)$ during the first month among those 
Table 2 Mean values of clinical and laboratory parameters observed on entry to study and after each treatment period, according to initial treatment given

\begin{tabular}{|c|c|c|c|c|}
\hline & Variable & Initial assessment & After DSCG treatment & After placebo treatment \\
\hline $\begin{array}{l}\text { DSCG_placebo group } \\
\text { (15 patients) }\end{array}$ & $\begin{array}{l}\text { Bowel frequency } / 24 \mathrm{hr} \\
\text { Rectal bleeding }(0-3) \\
\text { Sigmoidoscopy grade (1-4) } \\
\text { Seromucoid (mg/dl) }\end{array}$ & $\begin{array}{r}4 \cdot 66 \\
1 \cdot 13 \\
2 \cdot 8 \\
132\end{array}$ & $\begin{array}{l}3 \cdot 73^{*} \\
0 \cdot 7 \\
2 \cdot 7 \\
115 \dagger\end{array}$ & $\begin{array}{r}3 \cdot 03 \\
0 \cdot 47 \\
2 \cdot 4 \\
103\end{array}$ \\
\hline $\begin{array}{l}\text { Placebo-DSCG group } \\
\text { (11 patients) }\end{array}$ & $\begin{array}{l}\text { Bowel frequency } / 24 \mathrm{hr} \\
\text { Rectal bleeding (0-3) } \\
\text { Sigmoidoscopy grade (1-4) } \\
\text { Seromucoid (mg/dl) }\end{array}$ & $\begin{array}{r}4 \cdot 27 \\
1 \cdot 64 \\
3 \cdot 3 \\
139\end{array}$ & $\begin{array}{l}3 \cdot 09 \\
0 \cdot 86 \\
2 \cdot 3 \\
105\end{array}$ & $\begin{array}{l}3 \cdot 27^{*} \\
0 \cdot 73 \dagger \\
2 \cdot 5^{*} \\
116^{*}\end{array}$ \\
\hline
\end{tabular}

Comparison of initial assessment with that at the end of the first treatment period. ${ }^{*} \mathbf{P}<0.05 ; \dagger P<0.01$.

patients who received the active treatment first (Table 3).

Patient and clinician preferences for either treatment are shown in Table 4. Only in four cases did patient and clinician agree that disodium cromoglycate was the more effective treatment compared with a combined preference for the placebo treatment on seven occasions. There was no common characteristic(s) among these four patients to indicate that there was a subgroup of patients in whom the treatment might be more effective.

Table 3 Changes in biopsy ranking after each treatment period

\begin{tabular}{llll}
\hline & Worse & No change & Better \\
\hline First treatment period & & & \\
After disodium cromoglycate & 0 & 5 & 7 \\
After placebo & 1 & 5 & 3 \\
Second treatment period & & & \\
After disodium cromoglycate & 2 & 3 & 4 \\
After placebo & 4 & 5 & 4 \\
\hline
\end{tabular}

The biopsies from two patients in each group and the first biopsy from one patient in the active-placebo group were not suitable for assessment.

Table 4 Patient and clinician treatment preferences

\begin{tabular}{lllll}
\hline Clinician & \multicolumn{2}{l}{ Patient } & \multicolumn{2}{c}{$\begin{array}{l}\text { Clinician's } \\
\text { total }\end{array}$} \\
\cline { 2 - 4 } & DSCG & Placebo & Neither & \\
\hline DSCG & 4 & 0 & 1 & 5 \\
Placebo & 1 & 7 & 1 & 9 \\
Neither & 4 & 2 & 6 & 12 \\
Patient's total & 9 & 9 & 8 & 26 \\
\hline
\end{tabular}

The eosinophil density in the lamina propria was high in seven of the eight rectal biopsies assessed on entry to the study (mean 520 cells, range 279-1050 cells/sq cm lamina propria; normal, mean 70 cells, range 0-220 cells/sq $\mathrm{cm}$ lamina propria). There was almost a complete absence of eosinophils in the other biopsy. The initial eosinophil density in these eight patients did not correlate with their response to treatment during the trial.

No unwanted effects of disodium cromoglycate therapy were observed; one patient complained of nausea while taking the placebo treatment.

\section{Discussion}

The patients in this study were particularly resistant to conventional therapy and all continued to have active disease in spite of regular treatment with steroid retention enemas. If oral disodium cromoglycate confers a mild therapeutic effect it is possible that it would not become apparent in this clinical situation, but it is these patients who need an additional treatment. We chose the oral route of administration in this study because of the inconvenience of rectal treatment, particularly in patients already having regular steroid retention enema therapy. The dose, $800 \mathrm{mg}$, was selected as it was similar to that used by Heatley et al. (1975), with encouraging results in chronic proctitis. It is possible that rectal administration, as used in combination with oral therapy by Heatley and his colleagues in their study, allows more of the drug to come in contact with the inflamed mucosa with an increased therapeutic effect. Nonetheless, Mani et al. (1976) observed an improvement in their patients with total ulcerative colitis treated with oral disodium cromoglycate, although the dose, $2 \mathrm{~g}$ daily, was larger and the treatment period, six months, substantially longer.

Careful measurement of the eosinophil content of the lamina propria in the rectal biopsies of eight of the patients on entry to our trial showed that in seven there was a high eosinophil density. Heatley et al. (1975) found that those patients with a high eosinophil count in the rectal biopsy responded more frequently to disodium cromoglycate therapy, but in our patients this feature did not seem to be of prognostic value.

There was a significant tendency for the patients studied to improve during the trial regardless of 
whether active or placebo treatment was given. This probably results from the occurrence of spontaneous remissions, the stricter adherence by the patients to their treatment regimes during the trial, as well as from any 'placebo effect' and stresses the need for controlled observations.

It is possible that the use of a larger oral dose of disodium cromoglycate, a longer treatment period, rectal administration, or any combination of these three may allow a beneficial therapeutic effect to be demonstrated in patients with chronic persistent colitis. However, the absence of improvement in this study is not encouraging.

The authors thank Mrs M. J. Elvidge for performing the statistical analysis and Miss S. J. Mallett for typing the manuscript. N.A.B. was in receipt of a LOCR grant from the North East Thames Regional Health Authority, and S.R.G. was in receipt of a grant from the St Mark's Research Foundation, whose support is gratefully acknowledged.

\section{References}

Baron, J. H., Connell, A. M., and Lennard-Jones, J. E. (1964). Variation between observers in describing mucosal appearances in proctocolitis. British Medical Journal, 1, 8992.

Cooke, W. T., Fowler, D. I., Cox, E. V., Gaddie, R., and Meynell, M. J. (1958). The clinical significance of seromucoids in regional ileitis and ulcerative colitis. Gastroenterology, 34, 910-919.

Dronfield, M. W., and Langman, M. J. S. (1977). Controlled comparison of sodium cromoglycate and salazopyrin in the maintenance of remission in ulcerative colitis. Gut, 18, A973.

Heatley, R. V., Calcraft, B. J., Rhodes, J., Owen, E., and Evans, B. K. (1975). Disodium cromoglycate in the treatment of chronic proctitis. Gut, 16, 559-563.

Mani, V., Lloyd, G., Green, F. H. Y., Fox, H., and Turnberg, L. A. (1976). Treatment of ulcerative colitis with oral disodium cromoglycate. Lancet, 1, 439-441.

Morson, B. C. (1974). The technique and interpretation of rectal biopsies in inflammatory bowel disease. In Pathology Annual, pp. 209-230. Edited by S. C. Sommers. AppletonCentury-Crofts: New York. 